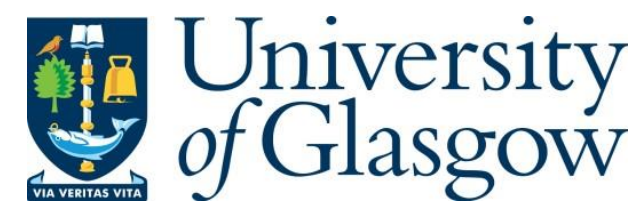

Matsue, Y. et al. (2017) Clinical correlates and prognostic value of proenkephalin in acute and chronic heart failure. Journal of Cardiac Failure, 23(3), pp. 231-239. (doi:10.1016/j.cardfail.2016.09.007)

This is the author's final accepted version.

There may be differences between this version and the published version. You are advised to consult the publisher's version if you wish to cite from it.

http://eprints.gla.ac.uk/129498/

Deposited on: 17 October 2016

Enlighten - Research publications by members of the University of Glasgow http://eprints.gla.ac.uk 


\section{Accepted Manuscript}

Title: Clinical Correlates and Prognostic Value of Pro-Enkephalin in Acute and Chronic Heart Failure

Author: Yuya Matsue, Jozine M. ter Maaten, Joachim Struck, Marco Metra, Christopher M. O'Connor, Piotr Ponikowski, John R. Teerlink, Gad Cotter, Beth Davison, John G. Cleland, Michael M. Givertz, Daniel M. Bloomfield, Howard C. Dittrich, Dirk J. van Veldhuisen, Peter van der Meer, Kevin Damman, Adriaan A. Voors

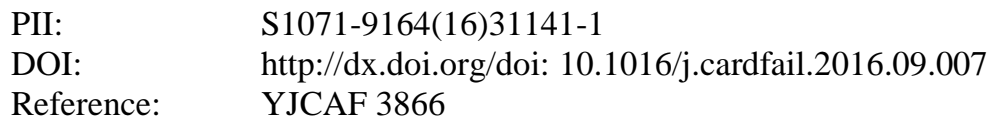

Received date: $18-5-2016$

Revised date: 6-9-2016

Accepted date: $13-9-2016$

Please cite this article as: Yuya Matsue, Jozine M. ter Maaten, Joachim Struck, Marco Metra, Christopher M. O'Connor, Piotr Ponikowski, John R. Teerlink, Gad Cotter, Beth Davison, John G. Cleland, Michael M. Givertz, Daniel M. Bloomfield, Howard C. Dittrich, Dirk J. van Veldhuisen, Peter van der Meer, Kevin Damman, Adriaan A. Voors, Clinical Correlates and Prognostic Value of Pro-Enkephalin in Acute and Chronic Heart Failure, Journal of Cardiac Failure (2016), http://dx.doi.org/doi: 10.1016/j.cardfail.2016.09.007.

This is a PDF file of an unedited manuscript that has been accepted for publication. As a service to our customers we are providing this early version of the manuscript. The manuscript will undergo copyediting, typesetting, and review of the resulting proof before it is published in its final form. Please note that during the production process errors may be discovered which could affect the content, and all legal disclaimers that apply to the journal pertain. 


\title{
Clinical Correlates and Prognostic Value of Pro-Enkephalin in Acute and Chronic Heart Failure
}

\author{
Yuya Matsue*, Jozine M. ter Maaten*, Joachim Struck†, Marco Metrał, \\ Christopher M. O’Connor§, Piotr Ponikowski ॥, John R. TeerlinkđI, Gad Cotter\#, Beth Davison\#, \\ John G. Cleland**, Michael M. Givertz $\uparrow \uparrow$, Daniel M. Bloomfield + , Howard C. Dittrich $\S$, \\ Dirk J. van Veldhuisen*,Peter van der Meer*, Kevin Damman*, Adriaan A. Voors*
}

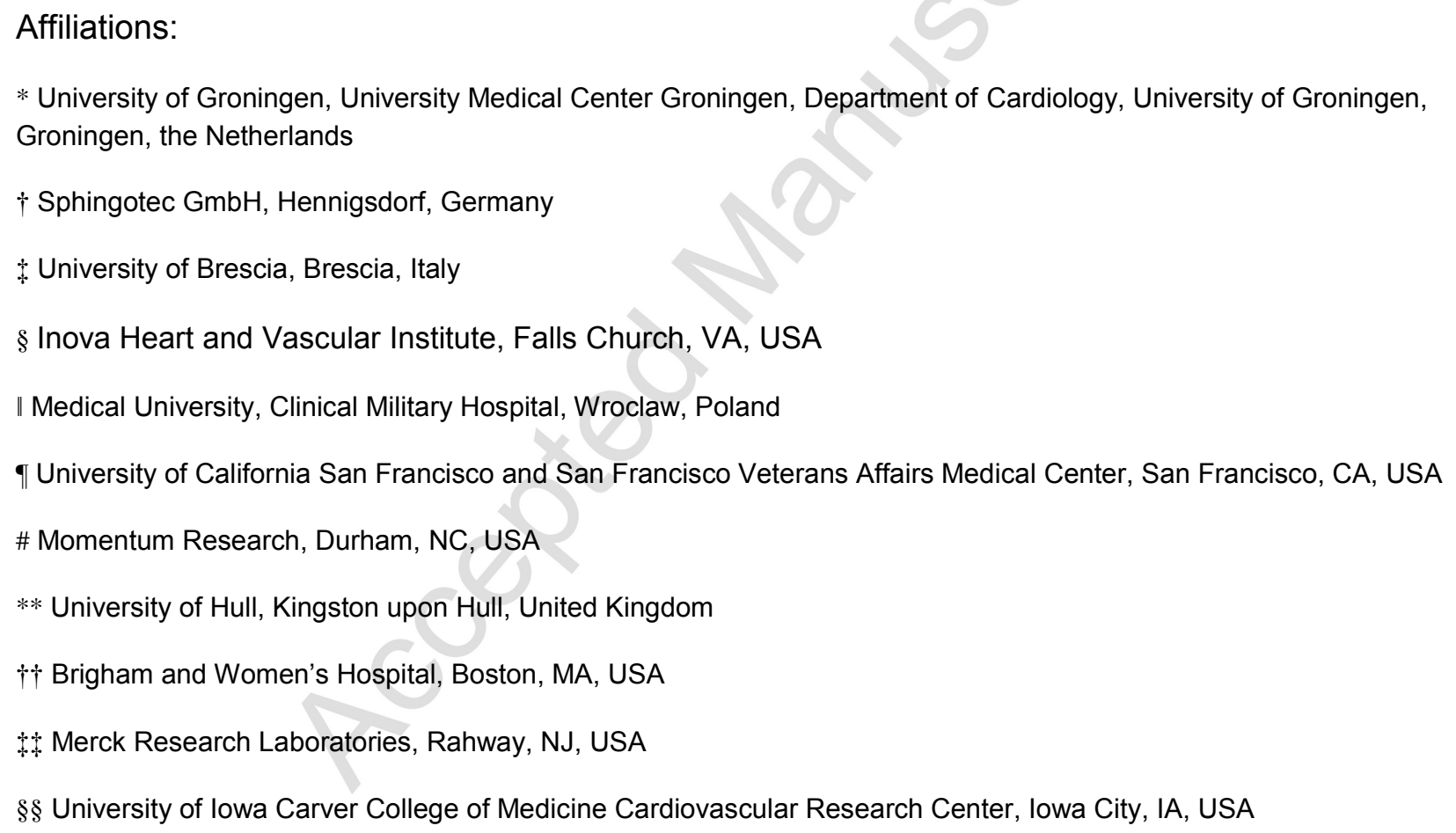

Corresponding author:
A.A. Voors, MD, PhD
Professor of Cardiology
Department of Cardiology, University Medical Center Groningen 
Hanzeplein 1, 9713 GZ, Groningen, The Netherlands

Tel: +31 (0)50 3616161; Fax : +31 (0)50 3618062; e-mail: a.a.voors@umcg.nl

Total word count: 5,977 words

Journal Subject Code: [10] Cardio-renal physiology/pathophysiology

Highlights:

- Clinical and prognostic role of pro-enkephalin has tested in chronic and acute heart failure.

- Pro-enkephalin was correlated with glomerular function but not with tubular dysfunction.

- Pro-enkephalin did not show an additive prognostic information on top of preexisting renal markers in acute heart failure.

\section{Abstract}

\section{Background}

Proenkephalin (pro-ENK) has emerged as a novel biomarker associated with both renal function and cardiac function. However, its clinical and prognostic value have not been well evaluated in symptomatic patients with heart failure.

\section{Methods and Results}

The association between pro-ENK and markers of renal function was evaluated in 95 patients with chronic heart failure who underwent renal hemodynamic measurements including renal blood flow (RBF) and glomerular filtration rate (GFR) using ${ }^{131}$ I-Hippuran and ${ }^{125}$ I-lothalamate clearances, respectively. The association between pro-ENK and clinical outcome in acute heart failure was assessed in another 1589 patients. Pro-ENK was strongly correlated with both RBF 
$(P<0.001)$ and GFR $(P<0.001)$, but not with renal tubular markers. In the acute heart failure cohort, pro-ENK was a predictor of death through 180 days, heart failure rehospitalization through 60 days, and death or cardiovascular or renal rehospitalization through day 60 in univariable analyses, but its predictive value was lost in a multivariable model, when other renal markers were entered in the model.

\section{Conclusions}

In patients with chronic and acute heart failure, pro-ENK is strongly associated with glomerular function, but not with tubular damage. Pro-ENK provides limited prognostic information in patients with acute heart failure on top of established renal markers.

Keywords: renal function; heart failure; prognosis; enkephalin

\section{Introduction}

Renal dysfunction is frequently observed in patients with heart failure ${ }^{1}$, and both baseline renal function and worsening of renal function accompanying inadequate decongestion during hospitalization is associated with prolonged hospitalization, rehospitalization, and death ${ }^{2,3}$.

Enkephalins including pro-enkephalin (pro-ENK) are small endogenous opioid peptides encoded by the proenkephalin gene, and have been shown to be implicated in neurotransmission, autocrine and paracrine function, and cardiac function. Most of the early studies have focused on its role in neuronal tissues, but it is also suggested to be produced and act in non-neural tissues including heart and kidney ${ }^{4}$. Due to the instability of enkephalins, a stable fragment of their precursor, termed pro-ENK, has been devised as stable and reliable 
surrogate plasma marker ${ }^{5}$. In patients with acute kidney injury after cardiac surgery, pro-ENK was shown to rapidly increase ${ }^{6}$. In acute myocardial infarction, increased pro-ENK was associated with renal dysfunction and predicted major cardiac events ${ }^{7}$. These results suggest a potential of pro-ENK as a novel cardiorenal biomarker, although its role in chronic and acute heart failure has not been established. Here, we evaluate the association between pro-ENK and indices of glomerular and tubular function and clinical outcome in patients with acute and chronic heart failure.

\section{Methods}

This study was performed in two populations. First, a cardiorenal mechanistic cohort was used to investigate the association between pro-ENK and renal function including hemodynamic parameters which were measured by radioactive tracers in patients with stable chronic heart failure $^{8,9}$. Second, the PROTECT (Placebo-controlled Randomized study of the selective A1 adenosine receptor antagonist rolofylline for the patients hospitalized with acute heart failure and volume Overload to assess Treatment Effect on Congestion and renal functTion) study cohort (acute heart failure cohort) was used to study the association between pro-ENK and prognosis in patients with acute heart failure ${ }^{10}$. Measurement of pro-ENK was performed using a sandwich immunoassay with antibodies against the proenkephalin A 119-159 peptide by Sphingotec inc. ${ }^{5,7}$. The lower detection limit was $5.5 \mathrm{pmol} / \mathrm{L}$. Intra- and inter-assay coefficients of variation were 6.4 and $9.5 \%$ at $50 \mathrm{pmol} / \mathrm{L}$, and 4.0 and $6.5 \%$ at $150 \mathrm{pmol} / \mathrm{L}$, respectively. The normal value of pro-ENK was measured in a general population, and determined as $46.6 \pm 14.1$ $\mathrm{pmol} / \mathrm{L}$ and median value of 45 (range: $9-518) \mathrm{pmol} / \mathrm{L}^{11}$. The $99^{\text {th }}$ percentile upper reference limit of pro-ENK in healthy subjects was $80 \mathrm{pmol} / \mathrm{L}^{11}$. 
Renal mechanistic cohort (chronic heart failure)

Patient selection and measurement procedure of renal hemodynamic parameters have been described elsewhere ${ }^{8,9}$. In brief, 120 ambulatory patients with heart failure with left ventricular ejection fraction (LVEF) $<45 \%$ on stable doses of ACE inhibitor or ARB for at least one month were included at University Medical Centre Groningen. All patients who consented to participate underwent GFR and effective renal plasma flow measurement using ${ }^{125}$ I-lothalamate and ${ }^{131}$ IHippuran. Renal blood flow (RBF) was calculated as effective renal plasma flow/1-haematocrit. GFR and RBF were expressed per body surface area. pro-ENK values were measured in 95 available plasma samples. Serum cystatin C levels were measured by nephelometry. Urinary tubular markers including neutrophil gelatinase-associated lipocalin (NGAL), N-acetyl-beta-Dglucosaminide for N-acetyl- $\beta$-D-glucosaminidase (NAG), and Kidney Injury Molecule 1 (KIM-1) were also determined by ELISA as previously described ${ }^{9}$.

\section{Acute heart failure cohort}

We also measured pro-ENK in the PROTECT study cohort. The details of the design, results, and conclusions of this study have already been published ${ }^{10,12,13}$. In brief, 2,033 patients with acute heart failure with renal function impairment (estimated creatinine clearance between 20 to $80 \mathrm{~mL} / \mathrm{min}$ with Cockcroft-Gault formula) were included and randomized to rolofylline or placebo. The protocol of the PROTECT study was approved by the ethics committee at each participating center, and written informed consent was obtained from all participants. We measured pro-ENK in 1,589 patients at baseline (day 1) 1,465 patients at day 2, and 1,200 patients at day 7 as samples were available. The following biomarkers were also evaluated at 
baseline; albumin, blood urea nitrogen (BUN), creatinine, glucose, hemoglobin, potassium, sodium, total cholesterol, triglycerides, uric acid and white blood cell count were measured by ICON Laboratories, Farmingdale, New York. N-Terminal pro Brain Natriuretic Peptide (NTproBNP) was determined by screening using commercial assays available at study sites. NGAL and C-reactive protein were measured in available frozen plasma samples by Alere Inc., San Diego, CA, USA. NGAL was measured using sandwich enzyme-linked immunosorbent assays (ELISA) on a microtiter plate; C-reactive protein was measured using a competitive ELISA on a Luminex platform.

We also evaluated the association between worsening renal function (WRF), pre-defined in PROTECT as a creatinine increase of $\geq 0.3 \mathrm{mg} / \mathrm{dL}$ from baseline (day 1 ) value or initiation of hemofiltration or dialysis at any time between day 1 to day 4 .

The prognostic value of pro-ENK was evaluated with 1,589 AHF patients with available ProENK value at baseline using three endpoints: all-cause mortality within 180 days, heart failure rehospitalization through 60 days, and death or cardiovascular or renal rehospitalization through day 60 days $^{14}$.

\section{Statistical analysis}

In both cohorts, data are expressed as mean and standard deviation for normally distributed variables, and as median with interquartile range for non-normally distributed data. Categorical data are expressed as numbers and percentages. The relationship between baseline characteristics and tertiles of pro-ENK were compared by using one-way analysis of variance test, Kruskal-Wallis test, or chi-squared tests where appropriate. A post-hoc test for pairwise comparison was performed with Bonferrroni correction. When necessary, variables were 
transformed for further analyzes. Stepwise multiple linear regression analysis was performed using backward elimination with a $\mathrm{P}$ value $<0.10$ as the criterion for retention after including all variables with $P$ value $<0.10$ in univariate analysis to identify factors independently associate to pro-ENK levels.

In the acute heart failure cohort, univariate logistic regression was performed to evaluate predictability of pro-ENK for WRF. If pro-ENK was significant in univariate logistic regression, multivariable logistic regression was performed to adjust for baseline creatinine levels to evaluate additive predictability for WRF. The longitudinal trajectory of pro-ENK over time (day 1, day 2 and day 7) was assessed by using linear mixed effect models to account for withinindividual correlation of repeatedly measured values of pro-ENK. For this analysis, we excluded patients who died within 7 days. Identification of subjects was included as random effects, and time was modeled linearly. We used age, previous heart failure hospitalization, peripheral edema, systolic blood pressure, serum sodium, log blood urea nitrogen, log creatinine, and albumin as fixed effects as these were suggested as factors of prognostic predictive value in this cohort ${ }^{15}$. For prognostic analysis, we adjusted log pro-ENK by a model that was previously defined for this cohort, including age, previous heart failure hospitalization, peripheral edema, systolic blood pressure, sodium, log blood urea nitrogen, log creatinine and albumin. ${ }^{15}$. In this cohort, predictability of this model was confirmed to be similar to more complex models for outcome of all-cause mortality within 180 days, death or rehospitalization for any reason within 30 days, and cardiovascular or renal rehospitalization within 30 days. We evaluated prognostic predict ability of pro-ENKN in three multivariable Cox models: adjusted for age and gender (Model 1), adjusted for age, gender, creatinine, and BUN (Model 2), and adjusted for the clinical model (Model 3). A two-tailed $P$ value $<0.05$ was considered statistically significant. Statistical analyses were performed using $R$ version 3.1.2 (R Foundation for Statistical Computing, Vienna, Austria). ISBN 3-900051-07-0, URL http://www.R-project.org. 


\section{Results}

\section{Renal mechanistic cohort}

\section{Patient characteristics}

Baseline characteristics are shown in Table 1. The mean age was $60 \pm 12$ years, 75 patients (79\%) were male, and mean LVEF was $29 \pm 10 \%$. The median value of pro-ENK was 62.2 (IQR: $48.5-92.5) \mathrm{pmol} / \mathrm{L}$ (Figure1), and $28(29.5 \%)$ patients had pro-ENK levels above $99^{\text {th }}$ percentile upper reference limit of pro-ENK in healthy subjects. Higher pro-ENK tertiles were associated with higher age, females, lower blood pressure, higher NYHA class, greater diuretics use and higher plasma NT-proBNP levels (all $P<0.05$ ).

\section{Correlation between renal markers and pro-ENK}

Supplemental Table 1 shows the result of univariate linear regression analysis between log proENK, renal markers and renal hemodynamic parameters. pro-ENK values were strongly and significantly associated with creatinine, BUN, Urinary Albumin Excretion, Cystatin C, GFR, and RBF but not with urinary tubular markers (NAG, NGAL, and KIM-1).

Table 2 shows the result of multivariable linear regression analysis for pro-ENK. In the final model $\left(R^{2}=0.616\right)$, higher log pro-ENK levels were associated with lower GFR (standardized beta $=-0.377$ ) higher BUN, higher NT-proBNP, lower NYHA class, and lower systolic blood pressure. 


\section{$\underline{\text { Acute heart failure cohort }}$}

\section{Patient characteristics}

Baseline characteristics of the PROTECT AHF cohort according to pro-ENK tertiles are shown in Table 3. The mean age was $71 \pm 11$ years, $1049(66 \%)$ were male, and mean LVEF was $33 \pm$ 13\%. The median value of pro-ENK was 104.9 (IQR: 73.7 - 146.6) pmol/L (Figure 1), and 1092 $(68.7 \%)$ patients had pro-ENK levels above $99^{\text {th }}$ percentile upper reference limit of pro-ENK in healthy subjects. At baseline, higher pro-ENK levels were associated with higher age, females, lower diastolic blood pressure, preserved LVEF $(\geq 45 \%)$, history of diabetes, higher creatinine, higher BUN, and higher brain natriuretic peptide (BNP).

\section{Correlation between covariates and pro-ENK}

The result of univariate and multivariable linear regression analysis of pro-ENK is shown in Supplemental Table 2 and Table 2, respectively. Serum creatinine was the primary determinant of log pro-ENK among baseline variables (standardized beta $=0.422, \mathrm{P}<0.001$ ), and followed by females, higher age, higher BNP, and higher BUN in PROTECT acute heart failure cohort.

\section{Association between pro-ENK and WRF}

High pro-ENK values at baseline were associated with a higher incidence of worsening renal function (Table 4). In univariate logistic regression, log pro-ENK was significantly associated with worsening renal function (Odds ratio: $1.47,95 \% \mathrm{Cl}: 1.18-1.84, \mathrm{P}<0.001$ ). However, the 
significance was attenuated after adjustment for log creatinine (Odds ratio: $1.24,95 \% \mathrm{Cl}$ : 0.951.61, $P=0.119)$. In a sensitivity analysis, log pro-ENK was not a significant predictor of WRF with other definitions ( $\geq 25 \%$ increase or $\geq 25 \%$ and $\geq 0.3 \mathrm{mg} / \mathrm{dL}$ increase in creatinine from baseline levels) even in a univariate logistic regression analysis (data not shown).

\section{Association of pro-ENK with prognosis}

Kaplan-Meier curves of each tertile for mortality through day 180 are shown in Figure 2. Higher tertiles of pro-ENK were associated with 180 days mortality $(P<0.001)$. In Cox regression models, high log pro-ENK levels were significantly associated with all of the three outcomes; death through 180 days, heart failure rehospitalization through day 60, and death or cardiovascular or renal rehospitalization through day 60 in univariable Cox regression analysis, and even after adjustment for age and gender (Model 1). Log pro-ENK was a significant predictor only for endpoint of death through day 180 even after being adjusted by age, gender, creatinine, and BUN (Model 2). However, log pro-ENK lost its significance for all of outcomes after adjustment for the PROTECT prognostic model; including age, history of heart failure hospitalization, severity of peripheral edema, systolic blood pressure, serum sodium, BUN, creatinine, and Albumin (Model 3) (Table 4). There was no significant interaction between rolofylline treatment and prognostic predictive ability of pro-ENK for any of outcomes (all P for interaction $>0.3)$.

\section{Serial changes in pro-ENK over time and prognosis}

We compared the trajectory of pro-ENK values at day 1 , day 2 , and day 7 and percent change from baseline to day 2 and day 7 between patients with and without death through 180 days 
after excluding 29 patients who died within 7 days of admission (Figure 3). Baseline pro-ENK value was higher in patients who died compared with those who were alive. In the mixed effect model, there was no significant difference between patients who died or survived with regard to absolute or relative changes over time $(P=0.760$ and $P=0.258$, respectively). Similar results were obtained for the endpoints of heart failure rehospitalization through 60 days and death or cardiovascular or renal rehospitalization through day 60 ( $P>0.05$ for all) (Supplemental Figure 1). We also evaluated the prognostic importance of percent change in pro-ENK from baseline (day 1) to day 2 and from baseline to day 7 as a numeric variable, and neither showed independent prognostic information in multivariate Cox regression analysis (Supplemental Table 3).

\section{Discussion}

In acute and chronic heart failure, pro-ENK levels were higher in acute HF compared with chronic HF. Pro-ENK was clearly associated with renal blood flow and glomerular filtration rate but not with tubular function. In patients with heart failure, pro-ENK was associated with clinical outcome, but after adjustments for established prognostic predictors including preexisting renal markers, this association was lost. Therefore, pro-ENK seems to be a renal marker, but does not seem to have additive value on top of the established prognostic markers.

\section{Pro-ENK as a renal biomarker in patients with heart failure}

The endogenous opioid system is one of the most studied innate pain-relieving systems. In addition, the endogenous opioid system has also been suggested to have a negative effect on the cardiovascular system. Two observational studies suggested that activity of the endogenous opioid system was activated in patients with heart failure compared with healthy subjects ${ }^{16,17}$. 
Additionally, in an experimental dog model of congestive heart failure, delta-opioid receptor (OPR) was specified as a more relevant receptor subtype among several OPRs in terms of hemodynamic regulation ${ }^{18}$. In this study, a selective antagonist for delta-OPR increased aortic pressure, cardiac output, and blood flow to the myocardium and kidney. These results suggested that delta-OPR plays a main role in the opioid system as a cardiovascular modulator, and measuring activity of enkephalin - a specific peptide to delta-OPR - might be useful to evaluate the effect of the opioid system in patients with heart failure. Recently, pro-ENK was suggested as a stable and reliable surrogate marker of enkephalin and it became possible to evaluate enkephalin activity in vivo ${ }^{5}$.

In the present study, we showed that levels of pro-ENK were relatively high in patients with both acute and chronic heart failure when pro-ENK value derived from normal subject was used as reference. Furthermore, both in the chronic and acute heart failure cohorts we found a consistent association between pro-ENK and several renal markers. Moreover, precise evaluation of renal function in the chronic heart failure cohort showed that pro-ENK levels were strongly associated with renal blood flow and glomerular filtration rate. These results are in agreement with the finding that delta-OPR was highly expressed in the kidney and inhibition of delta-OPR increased kidney blood flow in an experimental heart failure model ${ }^{4,18}$. Moreover, pro-ENK was positively correlated with albuminuria in the chronic heart failure cohort. These findings show that pro-ENK is a novel renal marker. The pathophysiologic mechanism or rather determinants of pro-ENK including renal clearance has to be evaluated in future studies.

We evaluated the association between pro-ENK and worsening renal function in acute heart failure, and found that pro-ENK was not a predictor of worsening renal function in patients with heart failure independent from serum creatinine. This is in line with a previous study that evaluated the association between pro-ENK values before surgery and acute kidney injury in 
patients undergoing cardiac surgery. In this study, baseline pro-ENK values were strongly associated with baseline creatinine. Pro-ENK levels were also associated with acute kidney injury after surgery, but did not outweigh creatinine ${ }^{6}$. These and our results showed that the association between pro-ENK and worsening renal function can be attributed to the significant association with creatinine, and pro-ENK by itself provides limited additive information to creatinine in terms of changes in renal function.

\section{Prognostic information of pro-ENK in heart failure}

In our present analysis, pro-ENK was not an independent predictor of prognosis in acute heart failure cohort in spite of its association with renal function and severity of heart failure. This result suggests that pro-ENK provides limited additional prognostic information to preexisting prognostic markers of patients with heart failure including renal biomarkers.

Our findings are inconsistent with previous two studies which investigated prognostic role of proENK in patients with myocardial infarction and non-symptomatic patients with heart failure, where higher pro-ENK levels were an independent predictor of a combined endpoint of death and adverse events even after adjustment for other prognostic factors ${ }^{7,19}$. This discordance might be due to a difference in study population. Another possible explanation is an association between pro-ENK and BUN. In the aforementioned study of myocardial infarction patients, proENK was an independent predictor of mortality after being adjustment for the Global Registry of Acute Coronary Events (GRACE) model ${ }^{20}$, and pro-ENK showed incremental prognostic information. However, the GRACE model does not include information about BUN, and as a consequence, it is unclear whether pro-ENK would have been a significant predictor of events if the model would have been adjusted for BUN. Recent studies showed that BUN was an 
independent predictor of mortality also in acute myocardial infarction patients even after being adjusted by eGFR ${ }^{21,22}$ and indeed pro-ENK was significantly and strongly correlated with BUN in our cohort. Recently, Arbit et al. investigated the role of pro-ENK in patients referred to echocardiography and categorized into stage A or B HF (symptomatic HF patients were excluded). Pro-ENK correlated with serum creatinine and eGFR, and was an independent predictor of worse prognosis after adjustment for some prognostic factors. However, in contrast to the present study, these patients were asymptomatic and were not adjusted for BUN, which was a strong confounder in our study ${ }^{19}$. The relationship between pro-ENK and BUN might be an explanation why pro-ENK was an independent prognostic predictor in these previous studies but not in our cohort.

\section{Limitations}

This study has important limitations due to its retrospective character. In the chronic HF cohort, number of patients were limited so that prognostic predictability of pro-ENK in a chronic heart failure population remains to be elucidated. In the acute heart failure cohort, only patients with heart failure with mild renal impairment were included by study design. Echocardiographic measurements were obtained in only less than half of all patients. Moreover, pro-ENK levels were not available in some patient of both cohorts due to availability of plasma, which could have influenced the results despite the fact that there was no significant difference in event rate for any endpoints between patients with available samples and those without (all $P$ value $>0.5$ ).

\section{Conclusion}


Pro-ENK levels were higher in acute heart failure when it compared with chronic heart failure. Pro-ENK levels were strongly associated with glomerular function and renal blood flow, but not with tubular damage. Pro-ENK has limited additive prognostic predictive information on top of existing renal markers in this cohort of acute heart failure.

Funding: The PROTECT trial was supported by NovaCardia, a subsidiary of Merck. Alere, Singulex, and Sphingotec kindly provided assays and performed biomarker measurements.

\section{Conflict of interest:}

Y.M., J.M.tM., K.D., and. have nothing to disclose. A.A.V. has received speaker/consultancy/research fees from Merck and NovaCardia, Singulex and Sphingotec. PvdM received consulting fees from Novartis, Vifor Pharma and ZS-pharma D.J.V.V. has received Board Membership fees from Amgen, BG Medicine, Biocontrol, Johnson \& Johnson, Novartis, Sorbent and Vifor. C.M.O.C. is a consultant to Merck. M.M. has received honoraria and reimbursements from NovaCardia, sponsors of the study, and from Merck, that purchased the rights to rolofylline after completion of the PROTECT pilot study. P.P. has received honoraria from Merck. J.R.T. has received research funds and consulting fees from Merck, the producer of rolofylline for the conduct of this study and has also received research funds and consulting fees from Abbott, Amgen, Biogen Idec, Corthera, Cytokinetics, Johnson and Johnson/ Scios, Novartis, Relypsa and Solvay for research in related areas. G.C. and B.D. are employees of Momentum Research Inc, which was contracted to perform work on the project by Merck \& Co, Inc. J.G.C. was on the Steering Committee for the study, served on the Advisory Board for MSD, and received payments for both. M.M.G. has received institutional research 
support and served on a scientific Advisory Board for Merck. D.M.B. is an employee of Merck. H.C.D was an employee of NovaCardia and a consultant to Merck.

\section{References}

1. Metra M, Cotter G, Gheorghiade M, Dei Cas L and Voors AA. The role of the kidney in heart failure. Eur Heart J. 2012;33:2135-2142.

2. Valente MA, Hillege HL, Navis G, Voors AA, Dunselman PH, van Veldhuisen DJ and Damman K. The Chronic Kidney Disease Epidemiology Collaboration equation outperforms the Modification of Diet in Renal Disease equation for estimating glomerular filtration rate in chronic systolic heart failure. Eur $J$ Heart Fail. 2014;16:86-94.

3. Testani JM, Coca SG, Shannon RP, Kimmel SE and Cappola TP. Influence of renal dysfunction phenotype on mortality in the setting of cardiac dysfunction: analysis of three randomized controlled trials. Eur J Heart Fail. 2011;13:1224-1230.

4. Denning GM, Ackermann LW, Barna TJ, Armstrong JG, Stoll LL, Weintraub NL and Dickson EW. Proenkephalin expression and enkephalin release are widely observed in non-neuronal tissues. Peptides. 2008;29:83-92.

5. Ernst A, Kohrle J and Bergmann A. Proenkephalin A 119-159, a stable proenkephalin A precursor fragment identified in human circulation. Peptides. 2006;27:1835-1840.

6. Shah KS, Taub P, Patel M, Rehfeldt M, Struck J, Clopton P, Mehta RL and Maisel AS.

Proenkephalin predicts acute kidney injury in cardiac surgery patients. Clin Nephrol. 2015;83:29-35.

7. Ng LL, Sandhu JK, Narayan H, Quinn PA, Squire IB, Davies JE, Bergmann A, Maisel A and Jones DJ. Proenkephalin and prognosis after acute myocardial infarction. J Am Coll Cardiol. 2014;63:280-289. 
8. Smilde TD, Damman K, van der Harst P, Navis G, Westenbrink BD, Voors AA, Boomsma F, van Veldhuisen DJ and Hillege HL. Differential associations between renal function and "modifiable" risk factors in patients with chronic heart failure. Clin Res Cardiol. 2009;98:121-129.

9. Damman K, Van Veldhuisen DJ, Navis G, Vaidya VS, Smilde TD, Westenbrink BD, Bonventre JV, Voors AA and Hillege HL. Tubular damage in chronic systolic heart failure is associated with reduced survival independent of glomerular filtration rate. Heart. 2010;96:1297-1302.

10. Massie BM, O'Connor CM, Metra M, Ponikowski P, Teerlink JR, Cotter G, Weatherley BD, Cleland JG, Givertz MM, Voors A, DeLucca P, Mansoor GA, Salerno CM, Bloomfield DM, Dittrich HC, Investigators $\mathrm{P}$ and Committees. Rolofylline, an adenosine A1-receptor antagonist, in acute heart failure. $N$ Engl J Med. 2010;363:1419-1428.

11. Marino R, Struck J, Hartmann O, Maisel AS, Rehfeldt M, Magrini L, Melander O, Bergmann A and Di Somma S. Diagnostic and short-term prognostic utility of plasma pro-enkephalin (pro-ENK) for acute kidney injury in patients admitted with sepsis in the emergency department. J Nephrol. 2015;28:717724.

12. Weatherley BD, Cotter G, Dittrich HC, Delucca P, Mansoor GA, Bloomfield DM, Ponikowski P, O'Connor CM, Metra M, Massie BM, Protect Steering Committee I and Coordinators. Design and rationale of the PROTECT study: a placebo-controlled randomized study of the selective A1 adenosine receptor antagonist rolofylline for patients hospitalized with acute decompensated heart failure and volume overload to assess treatment effect on congestion and renal function. J Card Fail. 2010;16:25-35. 13. Voors AA, Dittrich HC, Massie BM, DeLucca P, Mansoor GA, Metra M, Cotter G, Weatherley BD, Ponikowski P, Teerlink JR, Cleland JG, O'Connor CM and Givertz MM. Effects of the adenosine A1 receptor antagonist rolofylline on renal function in patients with acute heart failure and renal dysfunction: results from PROTECT (Placebo-Controlled Randomized Study of the Selective Adenosine A1 Receptor Antagonist Rolofylline for Patients Hospitalized with Acute Decompensated Heart Failure and Volume Overload to Assess Treatment Effect on Congestion and Renal Function). J Am Coll Cardiol. 2011;57:1899-1907.

14. Valente MA, Voors AA, Damman K, Van Veldhuisen DJ, Massie BM, O'Connor CM, Metra M, Ponikowski P, Teerlink JR, Cotter G, Davison B, Cleland JG, Givertz MM, Bloomfield DM, Fiuzat M, Dittrich $\mathrm{HC}$ and Hillege HL. Diuretic response in acute heart failure: clinical characteristics and prognostic significance. Eur Heart J. 2014;35:1284-1293.

15. Cleland JG, Chiswell K, Teerlink JR, Stevens S, Fiuzat M, Givertz MM, Davison BA, Mansoor GA, Ponikowski P, Voors AA, Cotter G, Metra M, Massie BM and O'Connor CM. Predictors of postdischarge outcomes from information acquired shortly after admission for acute heart failure: a report from the Placebo-Controlled Randomized Study of the Selective A1 Adenosine Receptor Antagonist Rolofylline for Patients Hospitalized With Acute Decompensated Heart Failure and Volume Overload to Assess Treatment Effect on Congestion and Renal Function (PROTECT) Study. Circ Heart Fail. 2014;7:76-87.

16. Kawashima S, Fukutake N, Nishian K, Asakuma S and Iwasaki T. Elevated plasma beta-endorphin levels in patients with congestive heart failure. J Am Coll Cardiol. 1991;17:53-58.

17. Fontana F, Bernardi P, Pich EM, Capelli M, Bortoluzzi L, Spampinato S and Canossa M.

Relationship between plasma atrial natriuretic factor and opioid peptide levels in healthy subjects and in patients with acute congestive heart failure. Eur Heart J. 1993;14:219-225.

18. Imai N, Kashiki M, Woolf PD and Liang CS. Comparison of cardiovascular effects of mu- and delta-opioid receptor antagonists in dogs with congestive heart failure. Am J Physiol. 1994;267:H912-

917.

19. Arbit B, Marston N, Shah K, Lee EL, Aramin H, Clopton P and Maisel AS. Prognostic Usefulness of Proenkephalin in Stable Ambulatory Patients With Heart Failure. Am J Cardiol. 2016;117:1310-1314. 
20. Eagle KA, Lim MJ, Dabbous OH, Pieper KS, Goldberg RJ, Van de Werf F, Goodman SG, Granger CB, Steg PG, Gore JM, Budaj A, Avezum A, Flather MD, Fox KA and Investigators G. A validated prediction model for all forms of acute coronary syndrome: estimating the risk of 6-month postdischarge death in an international registry. JAMA. 2004;291:2727-2733.

21. Kirtane AJ, Leder DM, Waikar SS, Chertow GM, Ray KK, Pinto DS, Karmpaliotis D, Burger AJ, Murphy SA, Cannon CP, Braunwald E, Gibson CM and Group TS. Serum blood urea nitrogen as an independent marker of subsequent mortality among patients with acute coronary syndromes and normal to mildly reduced glomerular filtration rates. J Am Coll Cardiol. 2005;45:1781-1786.

22. Aronson D, Hammerman H, Beyar R, Yalonetsky S, Kapeliovich M, Markiewicz W and Goldberg A. Serum blood urea nitrogen and long-term mortality in acute ST-elevation myocardial infarction. Int J Cardiol. 2008;127:380-385. 
Figure legends

Figure 1. Baseline pro-ENK values in renal mechanistic cohort and acute heart failure cohort

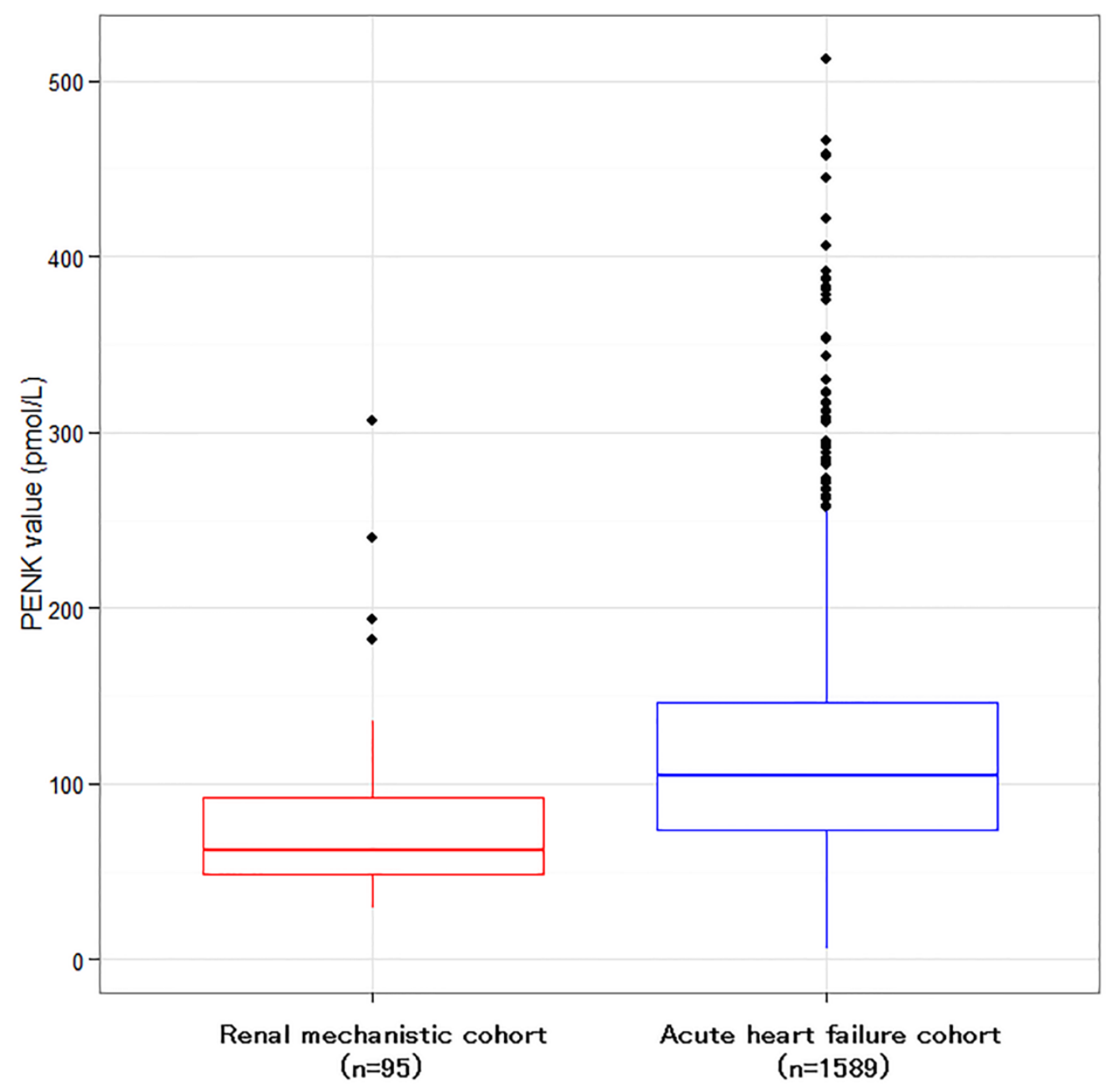

The box represent interquartile ranges, the horizontal line in each box represents the median, and the whiskers show the 10-90 percentile range. 
Figure 2. Kaplan-Meier curves of each tertile of pro-ENK in acute heart failure cohort

Kaplan-Meier curves of each tertileof pro-ENK in acute heart failure cohort

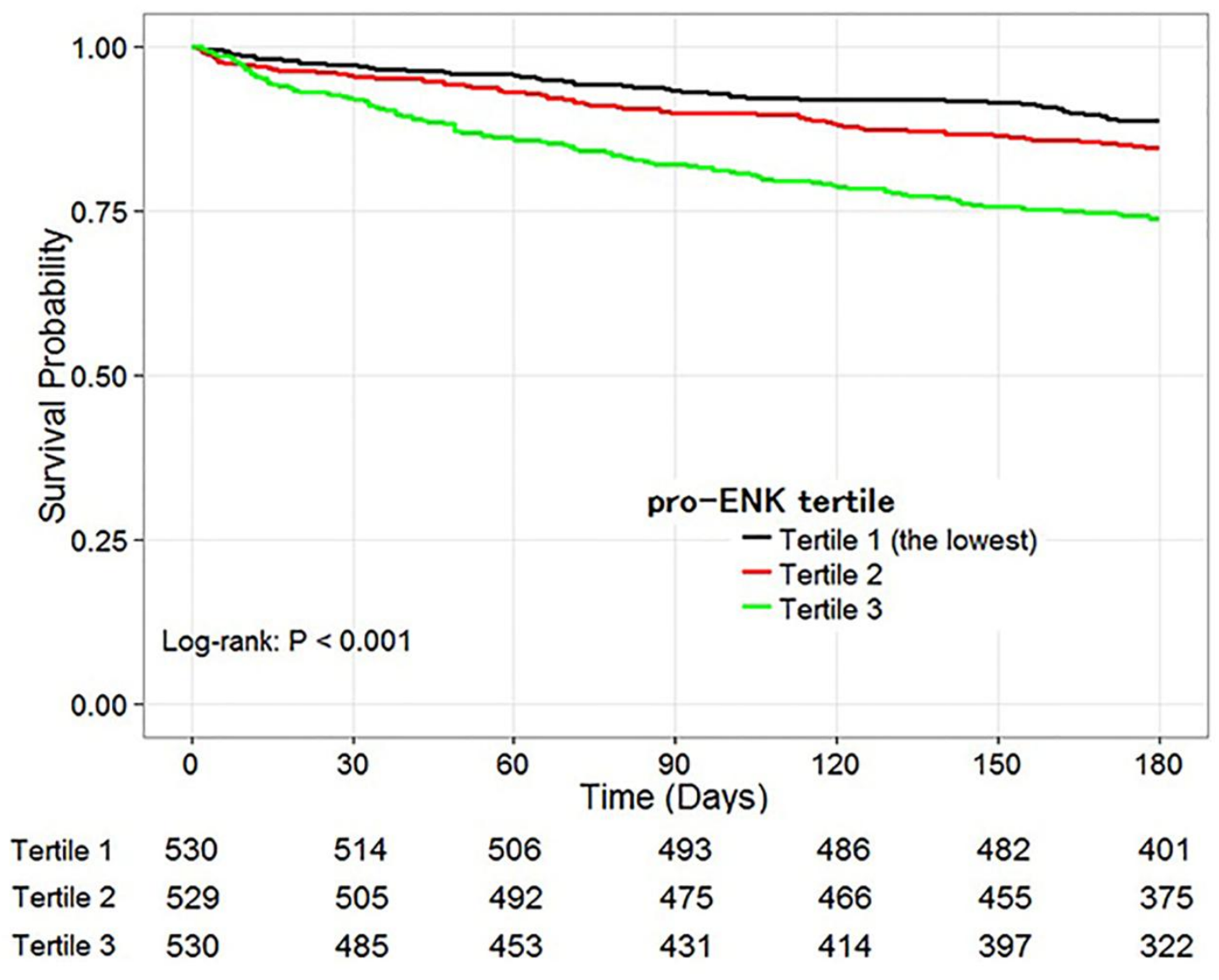

Survival curves of each pro-ENK tertile in acute heart failure cohort. 
Figure 3. Changes in pro-ENK in patients with and without death through 180 days
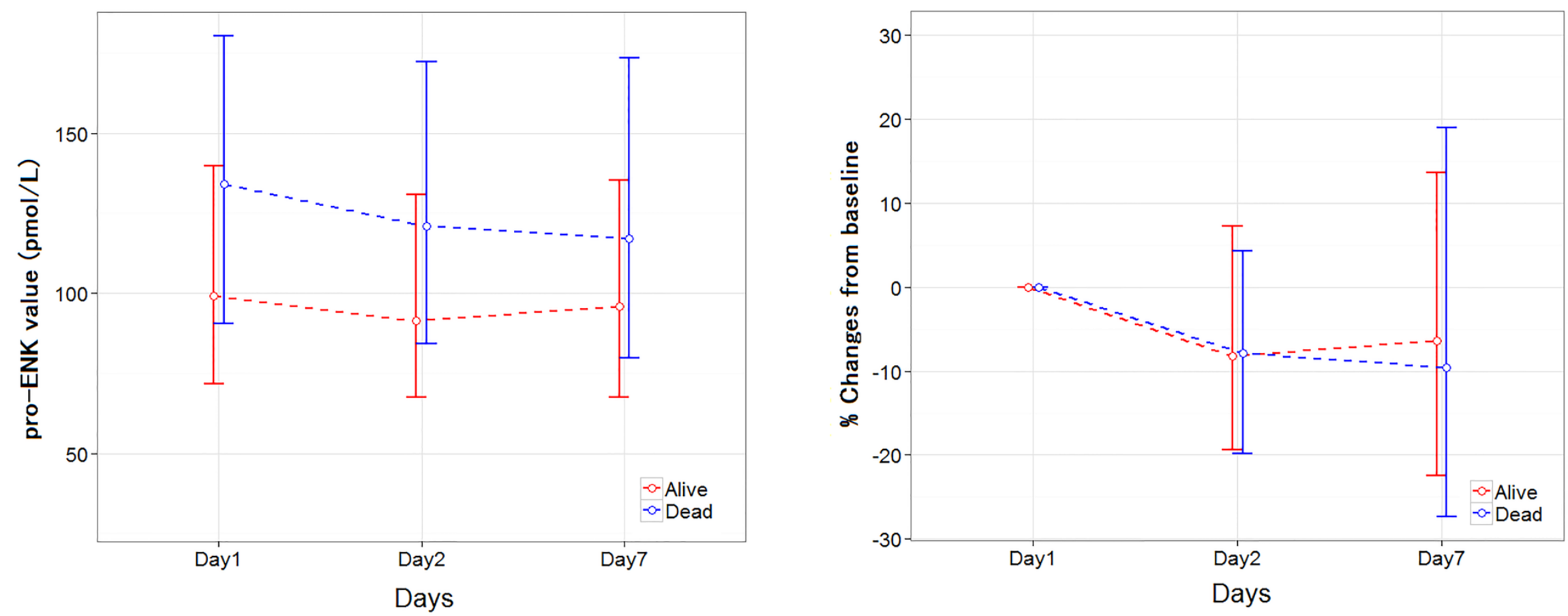

Median value is expressed as open circle and interquartile range is expressed as error bars. 
Table 1. Baseline characteristics and relationship between tertiles of pro-ENK in renal mechanistic cohort

\begin{tabular}{|c|c|c|c|c|c|}
\hline Variables & $\begin{array}{l}\text { All cohort } \\
\qquad(n=95)\end{array}$ & $\begin{array}{l}\text { Terile } 1 \\
(n=32)\end{array}$ & $\begin{array}{l}\text { Tertile } 2 \\
(n=31)\end{array}$ & $\begin{array}{l}\text { Tertile } 3 \\
(n=32)\end{array}$ & D \\
\hline $\begin{array}{l}\text { pro-ENK (median, [min-max], } \\
\mathrm{pmol} / \mathrm{mL} \text { ) }\end{array}$ & $62.2[29.3-306.6]$ & $45.7[29.3-53.2]$ & $62.2[53.5-75.5]$ & $102.5[76.1-306.6]$ & r value \\
\hline Age (yrs) & $60 \pm 12$ & $56 \pm 11 \dagger$ & $61 \pm 11$ & $63 \pm 12$ & 0.034 \\
\hline Male (\%) & $75(79)$ & $27(84)$ & $28(90) \div$ & $20(63)$ & 0.017 \\
\hline Body surface area (m2) & $2.0 \pm 0.2$ & $2.1 \pm 0.2 \dagger$ & $2.0 \pm 0.2$ & $1.9 \pm 0.2$ & 0.003 \\
\hline Systolic blood pressure (mmHg) & $120 \pm 21$ & $130 \pm 20 \dagger$ & $121 \pm 19 \ddagger$ & $109 \pm 20$ & $<0.001$ \\
\hline Diastolic blood pressure $(\mathrm{mmHg})$ & $69 \pm 12$ & $75 \pm 10 \dagger$ & $72 \pm 11 \div$ & $61 \pm 11$ & $<0.001$ \\
\hline Heart rate (bpm) & $65 \pm 13$ & $64 \pm 11$ & $65 \pm 15$ & $67 \pm 12$ & 0.815 \\
\hline Ischemic etiology (\%) & $52(55)$ & $15(47)$ & $20(65)$ & $17(53)$ & 0.363 \\
\hline Diabetes (\%) & $13(14)$ & $6(19)$ & $2(7)$ & $5(16)$ & 0.338 \\
\hline Smoking current or Ex (\%) & $47(49)$ & $13(43)$ & $19(63)$ & $15(52)$ & 0.297 \\
\hline NYHA III or IV (\%) & $34(36)$ & $4(13) \dagger$ & $11(36)$ & $19(59)$ & $<0.001$ \\
\hline LVEF (\%) & $29 \pm 10$ & $30 \pm 9 \dagger$ & $28 \pm 10$ & $27 \pm 10$ & 0.441 \\
\hline \multicolumn{6}{|l|}{ Medication } \\
\hline ACE-I (\%) & $78(82)$ & $27(84)$ & $27(87)$ & $24(75)$ & 0.419 \\
\hline ARB (\%) & $18(19)$ & $5(16)$ & $5(16)$ & $8(25)$ & 0.562 \\
\hline Beta blocker (\%) & $80(84)$ & $27(84)$ & $26(84)$ & $27(84)$ & 0.998 \\
\hline $\begin{array}{r}\text { Mineralocorticoid Receptor Antagonist } \\
(\%)\end{array}$ & $28(30)$ & $8(25)$ & $5(16) \div$ & $15(47)$ & 0.022 \\
\hline Diuretics (\%) & $63(66)$ & $18(56)$ & $18(58)$ & $27(84)$ & 0.029 \\
\hline Hemoglobin (g/dL) & $14.0 \pm 1.4$ & $14.3 \pm 1.1 \dagger$ & $14.0 \pm 1.0 \ddagger$ & $13.2 \pm 1.6$ & 0.001 \\
\hline Hematocrit (\%) & $42 \pm 4$ & $42 \pm 3 \dagger$ & $43 \pm 3+$ & $39 \pm 5$ & 0.001 \\
\hline
\end{tabular}




\begin{tabular}{|c|c|c|c|c|c|}
\hline NT-ProBNP (ng/L) & $\begin{array}{c}854.0 \\
(287.8-1911.5)\end{array}$ & $\begin{array}{c}370.4 \dagger \\
(204.6-829.6)\end{array}$ & $\begin{array}{c}431.1 \ddagger \\
(218.3-1210.0)\end{array}$ & $\begin{array}{c}1973.0 \\
(1186.3-3214.0)\end{array}$ & $<0.001$ \\
\hline \multicolumn{6}{|l|}{ Renal function } \\
\hline Creatinine $(\mathrm{mg} / \mathrm{dL})$ & $1.2(1.0-1.4)$ & $1.0(1.0-1.2) \dagger$ & $1.1(1.1-1.3) \ddagger$ & $1.5(1.2-1.8)$ & $<0.001$ \\
\hline BUN (mg/dL) & $20.4(16.7-29.1)$ & $16.7(14.2-19.2)^{*} \dagger$ & $19.9(18.4-22.4) \ddagger$ & $33.2(24.7-41.5)$ & $<0.001$ \\
\hline Cystatin C (mg/L) & $0.82(0.70-1.02)$ & $0.69(0.49-1.78)^{*} \dagger$ & $0.81(0.59-1.12) \ddagger$ & $1.19(0.64-2.09)$ & $<0.001$ \\
\hline GFR (mL/min/1.73m2) & $72.4 \pm 27.9$ & $92.2 \pm 23.4^{*} \dagger$ & $77.2 \pm 15.2 \%$ & $47.2 \pm 22.5$ & $<0.001$ \\
\hline $\mathrm{RBF}(\mathrm{mL} / \mathrm{min} / 1.73 \mathrm{~m} 2)$ & $450.1 \pm 162.2$ & $563.3 \pm 145.2^{*} \dagger$ & $470.7 \pm 94.4 \uparrow$ & $307.5 \pm 138.4$ & $<0.001$ \\
\hline $\mathrm{FF}(\%)$ & $28.0(25.0-29.9)$ & $28.4(25.8-30.1)$ & $28.3(26.6-29.2)$ & $26.5(20.4-29.6)$ & 0.122 \\
\hline Urinary KIM-1 (ng/gCr) & $\begin{array}{c}354.6 \\
(218.4-604.7)\end{array}$ & $\begin{array}{c}386.9 \\
(219.7-536.7)\end{array}$ & $\begin{array}{c}276.5 \\
(207.5-630.1)\end{array}$ & $\begin{array}{c}305.2 \\
(220.3-549.2)\end{array}$ & 0.909 \\
\hline Urinary NAG (U/gCr) & $12.9(6.5-16.9)$ & $13.3(6.0-17.2)$ & $10.3(6.5-12.8) \ddagger$ & $15.0(13.1-19.6)$ & 0.035 \\
\hline Urinary NGAL $(\mu \mathrm{g} / \mathrm{gCr})$ & $\begin{array}{c}177.6(61.1- \\
341.8)\end{array}$ & $\begin{array}{c}152.8(52.7- \\
314.0)\end{array}$ & $\begin{array}{c}187.7(79.9- \\
329.4)\end{array}$ & $\begin{array}{c}153.2(57.5- \\
366.5)\end{array}$ & 0.563 \\
\hline Urinary Creatinine $(\mathrm{mmol} / \mathrm{L})$ & $6.2(4.6-8.4)$ & $7.4(5.1-9.4)$ & $6.3(4.6-8.0)$ & $6.1(4.6-7.7)$ & 0.391 \\
\hline Urinary Albumin (mg/L) & $5.4(3.3-11.8)$ & $4.8(2.2-8.9) \dagger$ & $4.8(3.2-7.0) \dagger$ & $15.0(4.6-41.0)$ & 0.003 \\
\hline
\end{tabular}

$\uparrow P<0.05$, Tertile 1 vs Tertile 2

$\$ \mathrm{P}<0.05$, Tertile 1 vs Tertile 3

$\S \mathrm{P}<0.05$, Tertile 2 vs Tertile 3

ACE-I, angiotensin converting enzyme inhibitor; ARB, angiotensin II receptor blocker; BUN, blood urea nitrogen; GFR, glomerular filtration rate; KIM-1, kidney injury molecule 1; LVEF, left ventricular ejection fraction; NAG, N-acetyl-B-D-glucosaminidase; NGAL, neutrophil gelatinase-associated lipocalin; NT-proBNP, N-terminal pro-brain natriuretic peptide; NYHA, New York Heart Association; pro-ENK, proenkephalin 
Table 2. Multivariable linear regression for pro-ENK in renal mechanistic and acute heart failure cohort

\begin{tabular}{|c|c|c|c|}
\hline \multicolumn{4}{|c|}{ Multivariate linear regression for Log PENK } \\
\hline Variables & Standardized Beta & $\mathrm{t}$ & $P$ value \\
\hline \multicolumn{4}{|c|}{ Renal mechanistic cohort (Adjusted $\mathrm{R}^{2}=0.616$ ) } \\
\hline GFR per BSA & -0.377 & -3.189 & 0.002 \\
\hline Log BUN & 0.321 & 2.996 & 0.004 \\
\hline Log NT-proBNP & 0.284 & 3.092 & 0.003 \\
\hline NYHA III or IV & -0.245 & -2.617 & 0.010 \\
\hline Systolic blood pressure & -0.197 & -2.845 & 0.005 \\
\hline \multicolumn{4}{|c|}{ Acute heart failure cohort (Adjusted $\mathrm{R}^{2}=0.469$ ) } \\
\hline Creatinine & 0.445 & 14.30 & $<0.001$ \\
\hline Male & -0.21 & -9.647 & $<0.001$ \\
\hline Age & 0.163 & 7.583 & $<0.001$ \\
\hline BNP & 0.147 & 6.899 & $<0.001$ \\
\hline BUN & 0.119 & 3.819 & $<0.001$ \\
\hline Hemoglobin & -0.113 & -5.273 & $<0.001$ \\
\hline BMI & -0.097 & -4.507 & $<0.001$ \\
\hline Glucose & -0.085 & -4.167 & $<0.001$ \\
\hline Potassium & 0.077 & 3.687 & 0.002 \\
\hline Uric acid & 0.056 & 2.442 & 0.015 \\
\hline
\end{tabular}

BMI, body mass index; BNP; brain natriuretic peptide; BUN, blood urea nitrogen; GFR, glomerular filtration rate; NT-proBNP, Nterminal pro-brain natriuretic peptide; NYHA, New York Heart Association; pro-ENK, proenkephalin 
Table 3. Baseline characteristics according to tertiles of pro-ENK in acute heart failure (PROTECT) cohort

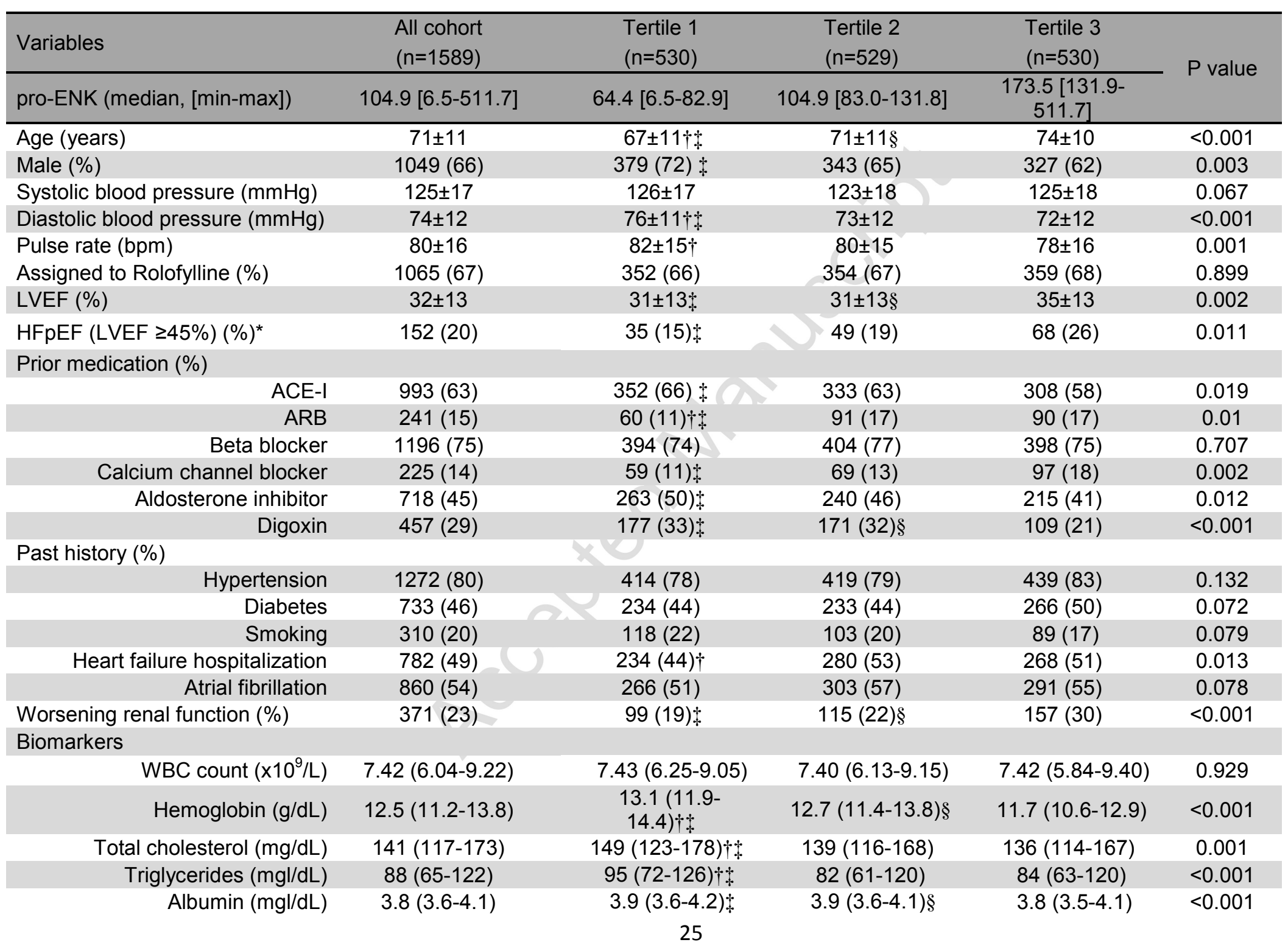




\begin{tabular}{|c|c|c|c|c|c|}
\hline BUN (mg/dL) & $30(22-41)$ & $22(18-28) \dagger+$ & $29(23-38) \S$ & $42(32-56)$ & $<0.001$ \\
\hline Creatinine (mg/dL) & $1.4(1.1-1.8)$ & $1.1(0.9-1.3) \dagger t$ & $1.4(1.2-1.6) \S$ & $1.8(1.5-2.3)$ & $<0.001$ \\
\hline NGAL (ng/mL) & $82.4(52.8-135.1)$ & $56.6(39.8-82.9)+t$ & $75.8(53.9-112.5) \S$ & $132.8(87.8-198.8)$ & $<0.001$ \\
\hline Sodium (mEq/L) & $140(137-142)$ & $140(137-143) \div$ & $140(137-142)$ & $139(137-142)$ & 0.013 \\
\hline Potassium (mEq/L) & $4.2(3.9-4.6)$ & $4.1(3.8-4.5) \ddagger$ & $4.2(3.8-4.6) \S$ & $4.3(3.9-4.8)$ & $<0.001$ \\
\hline Glucose (mg/dL) & $128(103-164)$ & $133(106-175) \dagger+$ & $124(101-162)$ & $126(101-160)$ & 0.008 \\
\hline Uric acid (mg/dL) & $8.8(7.2-10.6)$ & $7.9(6.6-9.5)+t$ & $8.9(7.3-10.6) \S$ & $9.6(7.9-11.6)$ & $<0.001$ \\
\hline BNP (pg/mL) & $\begin{array}{c}449.2 \\
(255.9-801.5)\end{array}$ & $\begin{array}{c}319.3+t \\
(201.6-556.6)\end{array}$ & $\begin{array}{c}510.9 \\
(277.8-854.9)\end{array}$ & $\begin{array}{c}542 \\
(293.9-968.9)\end{array}$ & $<0.001$ \\
\hline C-reactive protein $(\mathrm{ng} / \mathrm{mL})$ & $\begin{array}{c}13844 \\
(7271-27939)\end{array}$ & $\begin{array}{c}13683 \\
(6978-27339)\end{array}$ & $\begin{array}{c}13307 \\
(6956-27048)\end{array}$ & $\begin{array}{c}14707 \\
(8037-29315)\end{array}$ & 0.303 \\
\hline
\end{tabular}

${ }^{*} \mathrm{P}<0.05$, Tertile 1 vs Tertile 2

$\dagger \mathrm{P}<0.05$, Tertile 1 vs Tertile 3

$+\mathrm{P}<0.05$, Tertile 2 vs Tertile 3

ACE-I, angiotensin converting enzyme inhibitor; ARB, angiotensin II receptor blocker; BMI, body mass index; BNP, brain natriuretic peptide; BUN, blood urea nitrogen; HFpEF, heart failure with preserved ejection fraction; LVEF, left ventricular ejection fraction; NGAL, Neutrophil Gelatinase-Associated Lipocalin; pro-ENK, proenkephalin; WBC, white blood cell

*LVEF data was only available in $763(48.0 \%)$ patients. 
Table 4. Cox regression for outcomes in acute heart failure cohort

\begin{tabular}{|c|c|c|c|c|c|c|c|c|c|c|c|c|c|}
\hline \multirow[t]{2}{*}{ Outcomes } & \multirow[t]{2}{*}{$\begin{array}{l}\text { Number of } \\
\text { Events (\%) }\end{array}$} & \multicolumn{3}{|c|}{ Univariable } & \multicolumn{3}{|c|}{$\begin{array}{c}\text { Model } 1 \text { (adjusted by age } \\
\text { and gender) }\end{array}$} & \multicolumn{3}{|c|}{$\begin{array}{c}\text { Model } 2 \text { (adjusted by } \\
\text { Model } 1+\log \text { Creatinine } \\
\text { and } \log \text { BUN) }\end{array}$} & \multicolumn{3}{|c|}{$\begin{array}{l}\text { Model } 3 \text { (adjusted by } \\
\text { clinical model }{ }^{*} \text { ) }\end{array}$} \\
\hline & & HR & $95 \% \mathrm{Cl}$ & $P$ value & HR & $95 \% \mathrm{Cl}$ & $P$ value & HR & $95 \% \mathrm{Cl}$ & $P$ value & HR & $95 \% \mathrm{Cl}$ & $P$ value \\
\hline $\begin{array}{l}\text { Death through Day } \\
180\end{array}$ & $278(17.5)$ & 2.11 & $1.68-2.67$ & $<0.001$ & 2.02 & $1.59-2.57$ & $<0.001$ & 1.41 & $1.02-1.96$ & 0.039 & 1.23 & $0.91-1.66$ & 0.178 \\
\hline $\begin{array}{l}\text { Heart Failure } \\
\text { Rehospitalization } \\
\text { through Day } 60\end{array}$ & 227 (14.3) & 1.43 & $1.12-1.84$ & 0.005 & 1.53 & $1.18-1.97$ & 0.001 & 1.01 & $0.72-1.38$ & 0.933 & 1.01 & $0.74-1.36$ & 0.977 \\
\hline $\begin{array}{l}\text { Death or } \\
\text { Cardiovascular or } \\
\text { Renal } \\
\text { Rehospitalization } \\
\text { through Day } 60\end{array}$ & 457 (28.8) & 1.58 & $1.33-1.89$ & $<0.001$ & 1.63 & $1.36-1.96$ & $<0.001$ & 1.18 & $0.94-1.50$ & 0.162 & 1.15 & $0.91-1.45$ & 0.257 \\
\hline
\end{tabular}

BUN, blood urea nitrogen

* Adjusted for age, previous heart failure hospitalization, peripheral edema, systolic blood pressure, sodium, log blood urea nitrogen, log creatinine and albumin 